\title{
Espíritos, história e colonialismo na Guiana'
}

\section{Marcelo Moura Mello}

Universidade Federal da Bahia | Salvador, BA, Brasil

Em diálogo com proposições recentes em torno da antropologia da história, neste artigo abordo como espíritos de colonizadores holandeses na Guiana, antiga Guiana Britânica, atuam como agentes, atores e narradores do processo histórico. Argumento Espíritos, história, colonialismo, Guiana que espíritos participam da formulação, (re)criação e circulação de conhecimentos, fatos e experiências associados, pelos espíritos e pelos humanos, ao período colonial da Guiana.

Spirits, history and colonialism in Guyana 
$\mathrm{Na}$ introdução a um volume recente sobre a morte no Caribe, Maarit Forde evoca diversas ordens de rememoração de massacres em uma região asfixiada e sufocada por aquilo que chamou de "eventos inaugurais", isto é, o extermínio de populações autóctones, a escravidão e o trabalho sob contrato (indentured labour). Longe de serem singulares, tais eventos fundaram sociedades coloniais de plantação, cujas bases se assentaram na coerção, na violência e nos deslocamentos forçados (Forde, 2018). Reivindicando a necessidade de se prestar suficiente atenção aos contextos sociopolíticos nos quais as populações caribenhas se comunicam com mortos e (re) lembram destes, Forde conclama especialistas a analisar os impactos de transformações sociais, culturais, políticas e econômicas na própria conceituação dos mortos. Tratase, e aqui convém evocar o fascinante trabalho de Brown (2008) sobre as políticas mortuárias na Jamaica, de redimensionar problemáticas em torno da morte em sociedades construídas sobre os escombros de perdas coletivas (Brown 2010).

Tais perspectivas parecem-me rentáveis, pois apontam para as dimensões profundamente históricas das relações com os mortos em contextos-como o do Caribe - nos quais mortes violentas, brutais e inquietantes geraram não apenas metáforas e alegorias que aludem às perdas do passado, mas também presenças continuadas de seres que, não obstante seu caráter presumivelmente espectral, têm existência concreta no mundo (Kwon, 2008). Neste artigo, tomo como personagens centrais espíritos cujas existências históricas são indissociáveis tanto do estabelecimento da ordem colonial quanto dos efeitos duradouros de eventos inaugurais no presente. Interesso-me, em específico, em analisar como espíritos de colonizadores holandeses participam de formas de criação, circulação, transmissão e inscrição de conhecimentos sobre o passado colonial da Guiana, antiga Guiana Britânica.

Colônia britânica até 1966, ano da independência, a República Cooperativa da Guiana (Guyana) é composta por três regiões - Essequibo, Demerara e Berbice - que foram originalmente colonizadas por holandeses, entre 1665 e 1803. Neste ano, os britânicos assumiram o controle formal das três colônias, unificando-as em 1831, dando origem à Guiana Britânica. Enquanto o processo de transferência do domínio holandês para o britânico é retratado pela historiografia oficial e profissional como relativamente pacífico, sem grandes atribulações, os(as) moradores(as) contemporâneos da região costeira da Guiana apresentam imagem bastante diferente, dando destaque à ocorrência de um massacre.

De acordo com uma narrativa muito difundida no país, na transição do domínio holandês para o britânico, centenas de holandeses foram brutalmente assassinados por britânicos, ao passo que famílias inteiras teriam se suicidado para escapar de assassinatos, estupros, razias e outras formas de violência. Despossuídos de riquezas, terras, bens e propriedades, os holandeses também não receberam os serviços fúnebres adequados. Considerados os senhores, ${ }^{2}$ ou donos, da terra [masters of the land ou master boundaries], contemporaneamente esses espíritos buscam reter o domínio sobre as

2 | Neste texto, expressões, termos e categorias nativas são grifadas em itálico, apenas quando de sua primeira ocorrência. 
propriedades possuídas por colonizadores holandeses no passado, particularmente em áreas onde existiram, ou ainda existem, plantações de cana-de-açúcar³. Espíritos holandeses portam consigo memórias de atos violentos, infligindo ataques nos vivos. Imersos na vida mundana, contribuem para sentimentos e sensações inexplicáveis, comportamentos erráticos e autodestrutivos, além de estimularem ideações suicidas ${ }^{4}$. Não raro, os espíritos (tanto de homens quanto de mulheres) contraem relações sexuais com humanos no plano onírico, além de provocarem doenças, confusões mentais e desejos desmedidos - compulsão pelo consumo de drogas ou bebidas alcoólicas, libido aflorada, pensamentos obsessivos, etc. Em suma, e para se utilizar de um termo amplamente empregado entre meus interlocutores e minhas interlocutoras principais, espíritos holandeses afetam [affect] e produzem afetações [affections], coagindo as vítimas de seus ataques a entrar em contato direto com legados e heranças do passado colonial.

Vim a saber da existência de espíritos holandeses na Guiana um tanto espontaneamente, já no meu primeiro final de semana no país, durante pesquisa de campo exploratória ${ }^{5}$. Nessa etapa inicial da pesquisa, referências a espíritos dos mortos abundavam, inclusive porque eu estava hospedado, sem saber até então, em uma casa considerada mal-assombrada. À medida que fui me familiarizando com o país, travei contato com dezenas de pessoas sujeitas a ataques espirituais, sobretudo após iniciar minha pesquisa junto a descendentes de indianos e indianas que são membros de uma vertente hindu heterodoxa, o culto à deusa Kali. Documentei extensamente o caso de oito pessoas, obtendo informações sobre suas relações com espíritos ao longo do tempo, ora no templo hindu onde concentrei minhas observações, Blairmont, ora nas residências de indo-guianeses. ${ }^{6}$ Independentemente dos desdobramentos de cada relação em particular, aos poucos ficou evidente que as biografias de vários homens e de várias mulheres da Guiana não estavam apartadas da agência dos espíritos, nem de suas heranças.

Como demonstrarei nas próximas páginas, as reverberações do passado colonial são dimensionadas, por muitos guianenses, à luz dos efeitos produzidos por espíritos no presente. Na medida em que espíritos dos mortos, como notou Wirtz (2016), não apenas narram e reencenam o passado, mas também afetam o presente como copresenças imanentes aos vivos, sugiro que na Guiana contemporânea espíritos holandeses atuam como agentes, atores e narradores do processo histórico (Cf. Trouillot, 2016 [1995]). Suas estórias vinculam conhecimentos históricos sobre o passado colonial que são corporalmente experenciados por humanos. Em paralelo, humanos narram e dimensionam suas próprias estórias - como aquelas de ocupação territorial - à luz dos efeitos produzidos por espíritos no mundo.

Apesar do impacto de obras como a de Sahlins (1985) e do vasto acúmulo, nas últimas décadas, de estudos antropológicos que propõem intersecções com a história em termos mais amplos, o enfoque nas dimensões históricas de toda e qualquer sociedade nem sempre foi acompanhado de um exame mais minucioso sobre o
3 | Saliento de antemão que tal perspectiva é hegemônica na região costeira da Guiana, não abrangendo as percepções de coletivos ameríndios, que em sua maioria vivem em áreas de floresta. Para concepções ameríndias sobre domínio, poder e maestria na região das Guianas, ver, dentre outros: Mentore (2018), Rivière (1981), Vidal e Whitehead (2004) e Whitehead (2002).

4 | A Guiana tem uma das maiores taxas per capita de suicídios do mundo. Para um balanço recente, ver Edwards (2016). Em outro lugar, analisei um caso de suicídio precipitado por espíritos holandeses (Mello, 2021). Para uma análise sobre a relação entre espíritos e suicídios em socialidades indígenas, ver Matos (2017) e Pechincha (2018)

5| Realizei dez meses de pesquisa de campo na Guiana entre 2010 e 2012. Travei contato com membros do culto à deusa Kali na metade final de minha pesquisa de campo exploratória, conduzida entre janeiro e abril de 2010. A esse contato inicial somam-se mais oito meses de pesquisa de campo intensiva com membros do culto à Kali. Em 2018, retomei brevemente ao país, por pouco mais de 40 dias.

6| Descendentes de trabalhadores e trabalhadoras sob contrato da Índia que desembarcaram no país entre 1838 e 1917. Indoguianenses - que chamam a si mesmos(as) de indianos [Indian]-constituem o segmento populacional demograficamente mais representativo da Guiana. 
que os observadores entendem, em primeiro lugar, por história (Stewart e Hirsch, 2005). Foge a meus interesses enveredar por essa direção, ou de colocar à prova, a partir das ações de espíritos no mundo, primados caros aos modos profissionais de historicização do passado (Cf. Palmié, 2002; 2013). Em diálogo com as proposições de Palmié e Stewart (2016) em torno da antropologia da história, proponho descrever práticas por meio das quais se produz e se adquire conhecimento sobre o passado, bem como investigar ações, técnicas e sensações por meio das quais as pessoas sentem que estão em contato com o passado (ver também Lambek, 2016; Palmié e Stewart, 2019; Stewart, 2016).

Para proceder à minha análise, o texto está estruturado da seguinte maneira. Primeiramente, demonstro como o passado colonial holandês permanece significativo para guianenses contemporâneos, cujas narrativas sobre esse período são informadas por conhecimentos diversos acerca de eventos históricos, sobre a intervenção colonial na paisagem e sobre as ações de colonizadores europeus no passado. Em seguida, volto minha atenção para as estórias que descendentes de indianos - em particular, membros do culto à deusa hindu Kali-contam sobre espíritos e sobre formas de ocupação do território. Por fim, as considerações finais são precedidas por uma análise mais detida sobre as formas de comunicação corporificada entre espíritos e humanos.

\section{LECADOS HOLANDESES}

Vestígios materiais da colonização holandesa na Guiana abundam em toda a região costeira do país, cujas fundações repousam em um complexo sistema de eclusas (kokers), diques, canais e muros de contenção erigido tanto para conter o avanço da maré - a Guiana situa-se abaixo do nível do mar - quanto para evitar o acúmulo de água em áreas habitadas e de cultivo. A necessidade de regular o fluxo das águas estruturou o próprio padrão de distribuição da população no país (Smith, 1956), concentrada que está em uma estreita, e fértil, faixa territorial ${ }^{7}$ litorânea na qual grandes empreendimentos agroindustriais, as plantações, foram estabelecidos no passado. Dadas essas condições ecológicas, o cultivo em larga escala de produtos agrícolas requereu a importação de técnicas de engenharia dos Países Baixos. No processo de "humanização da região costeira" da Cuiana, para citar aqui a apropriada terminologia de Rodney (1981: 3), o trabalho fundacional de escravizados foi determinante ${ }^{8}$.

Toda essa infraestrutura hidráulica, em operação até hoje, é assaltada por outras forças e formas - aquelas da natureza, diria Simmel (1958 [1912]) - que corroem toda sorte de edificações: kokers necessitam de reparos constantemente; o muro de contenção está deteriorado em vários pontos; os canais mostram-se inoperantes face às constantes chuvas torrenciais que castigam o país; e à exceção de alguns poucos espaços turísticos, poucos prédios da época holandesa permanecem em pé hoje. De igual

7| Mais de $95 \%$ da população guianense, de aproximadamente 800.000 pessoas, está concentrada em $4 \%$ do território total do país, na região costeira. O estabelecimento de empreendimentos agroindustriais encerrou a vida da maior parte da população guianense em uma zona limítrofe (uma fronteira, se quisermos) entre o oceano $\mathrm{e}$ as áreas de floresta do país.

$8 \mid$ Sob tais condições, o trabalho envolvido na criação de terrenos aráveis foi hercúleo. Milhões de toneladas de terra e demais detritos foram extraídos do solo. Na construção de toda essa infraestrutura, lembra-nos Rodney (1981: 3), "escravos moveram 100 milhões de toneladas de areia sólida, encharcada de água, com pás em mãos, enquanto enfrentavam condições perpétuas de lama e água". Posteriormente trabalhadores sob contrato da Índia também tiveram por encargo a manutenção de diques e canais,

experimentando a "dieta de lama e água" em sua rotina diária de trabalho (idem, id.). 
modo, e não obstante a constante referência ao "legado holandês" (Dutch heritage) em cartilhas governamentais, manuais escolares e guias turísticos, é um segredo público que parte considerável dos documentos históricos da época holandesa ou foi consumida por insetos, ou encontra-se indisponível para consulta no arquivo nacional, o Walter Rodney Archives.

$O$ arquivo nacional se localiza nas proximidades da Square of Revolution, uma das praças centrais da capital, Georgetown. Nessa praça, a escultura de Cuffy (Coffij, nas fontes holandesas), um dos líderes da Revolta de Escravizados em Berbice, entre 1763 e 1764 , destaca-se pela imponência. $\mathrm{O}$

monumento, construído pelo artista afro-guianense Philip Moore (1921-2012), representa, de modo não-naturalista, um guerreiro africano com uma faca atada à cintura, cujo corpo corrugado é entalhado com máscaras. As placas ao redor do plinto evocam, dentre outras coisas, o mundo espiritual africano, a ganância dos plantadores holandeses e a resistência de escravizados. O monumento artístico foi encomendado pelo controverso presidente e primeiro-ministro Forbes Burnham"11 (1923-1985), cuja propaganda nacionalista, no rescaldo do conturbado processo de independência do Reino Unido, em $1966^{12}$, envolveu a ressignificação retrospectiva de vários eventos passados, como aqueles associados à luta pela liberdade de africanos no passado. Não à toa, a proclamação da República, no dia 23 de fevereiro de 1970, se deu no mesmo dia em que, supostamente, a revolta teria se iniciado, em 1763 (Thompson, 2006). Não à toa, tanto Burnham quanto outras lideranças independentistas produziram escritos sobre a Rebelião para extrair lições para o presente e, por extensão, para o futuro de uma nação recém-soberana (Williams, 2020 [1990]).

A quase-exitosa rebelião de Berbice durou mais de um ano e envolveu praticamente toda a população escravizada, de aproximadamente 4.000 pessoas, da então colônia holandesa. Após a eclosão de um levante inicial, em algumas semanas os rebeldes controlaram territorialmente Berbice, impelindo as forças holandesas a abandonar dezenas de plantações e dois fortes militares. Sitiadas em Dageraad, uma plantação localizada à montante do Rio Berbice, as tropas holandesas aguardaram
9| Todas as fotos aqui inseridas são de minha autoria.

o| O mapa é de 1720 , de autoria de Jan Daniel Knapp.

11 O regime de Burnham é apontado como responsável pelo assassinato, por meio de um atentado a bomba, do eminente historiador guianense Walter Rodney (1942-1980), cuja atuação política pregava a união da classe trabalhadora para além das divisões étnico-raciais do país. Rodney era crítico ferrenho do regime ditatorial de Burnham. Para um balanço recente, ver Taylor (2020).

12| A comunhão inicial de afro e indo-guianenses, os principais segmentos populacionais do país, na luta anticolonial ganhou expressividade já na década de 1950. Entretanto, disputas internas, fomentadas pelos serviços secretos britânico e estadunidense, que temiam as orientações comunistas do movimento anticolonial, fragmentaram o movimento independentista. Suas principais lideranças, o advogado afro-guianense Forbes Burnham, e o dentista indo-guianenses Cheddi Jagan, tornaram-se rivais e 0 partido independentista, o PPP (People's Progressive Party), se dividiu em linhas étnicas. A escalada de animosidades 
ansiosamente por reforços militares. Entrementes, Simon van Hoogenheim, governador da colônia, trocou missivas com Cuffy e Accabre, líderes da revolta que, inicialmente, demandaram a partida imediata dos holandeses da colônia e, em seguida, propuseram a criação de dois estados soberanos - um governado por negros, o outro, por brancos. ${ }^{13}$ Embora nenhum tratado tenha sido concluído, van Hoogenheim deliberadamente continuou a trocar missivas com Cuffy, enquanto requisitava, e aguardava, por suporte militar adicional.

Ao cabo, a Revolta de Berbice não logrou sucesso e os esforços revolucionários foram duramente reprimidos pelas forças coloniais, que foram reforçadas por batalhões de soldados de colônias vizinhas, da metrópole e de ameríndios ${ }^{14}$. Estima-se que entre um terço e um quinto da população escravizada sobreviveu à rebelião e a seu desfecho, enquanto um terço das plantações foi abandonada pelos colonizadores, cujo contingente populacional, de aproximadamente 350 pessoas, foi reduzido à metade (Kars, 2020: 254; 260). Após os últimos grupos de insurgentes serem debelados, centenas de rebeldes e suspeitos de participarem da revolta foram julgados e interrogados. Além dos castigos físicos infligidos a centenas de pessoas, 120 homens e 4 mulheres foram condenados à pena capital (Kars, 2020: 254).

Nos "sangrentos meses após a rebelião", nos lembra Brackette Williams (2020: 201), rebeldes foram "escaldados, queimados em chamas, cozinhados em fogo brando ou decapitados, com os restos de seus membros despedaçados". Suas cabeças, e partes extirpadas de seus corpos, "foram encravadas em estacas", para servir de exemplo e alerta. Não seria de espantar que humanos tratados tão injustamente em seus momentos derradeiros se tornassem incapazes de descansar pacificamente no mundo dos mortos, sugere Williams. No entanto, complementa, "não são [...] esses homens e essas mulheres que se tornaram fantasmas buscando reparações ou a compaixão dos vivos". Ao contrário, são os espíritos de homens e mulheres holandeses que "têm vagado [...] pela terra, buscando modos de reivindicar sua propriedade, de vingar suas mortes repentinas e/ou receber um funeral adequado" (Williams, 2020: 220). Para Williams, embora muitos desses espíritos tenham sido produto direto dos eventos imediatos da rebelião, outros surgiram de suas consequências duradouras. Suas estórias, contadas por meio dos indivíduos que os espíritos possuíam, "contrastam o poder e a posição social que tinham em Berbice antes da rebelião ao seu derradeiro 'lugar' social, político e econômico no mundo social que se seguiu à revolta" (idem: 195).

Com efeito, a Rebelião de Berbice fragilizou o domínio holandês na região, que nunca fora totalmente estável até então (Klooster e Oostindie, 2018; Williams, 2020). Entre 1781 e 1803, Berbice, assim como Essequibo e Demerara, foram controladas, sucessivamente, por holandeses, franceses e britânicos, até estes últimos formalizarem, em 1803, seu domínio sobre as três colônias, consolidando a ascendência política e financeira de que já gozavam na região desde o último quartel do século XVIII (Oostindie, 2012). Nas décadas imediatas à Rebelião de Berbice, a massiva

\author{
entre indo-guianeses e \\ afro-guianenses resultou \\ em conflitos campais, que \\ vitimaram centenas de \\ pessoas. A animosidade entre \\ os dois grupos é marcada \\ até hoje (ver, dentre outros, \\ Hintzen, 1989; Smith, 1995; \\ Trotz, 2003; Williams, 1991). \\ 13 É bem provável que \\ as lideranças da Rebelião \\ tivessem ciência dos tratados \\ de paz firmados pelas \\ administrações coloniais \\ da Jamaica e do Suriname \\ com as populações maroons \\ ('quilombolas'), que \\ garantiram certa autonomia \\ territorial às comunidades \\ de fugitivos (Kars, 2020). \\ 14 | Ver Farage (1991) e \\ Whitaker (2016) acerca das \\ redes históricas de relações \\ ameríndias na região.
}


injeção de mão-de-obra escravizada e de investimentos britânicos nas três colônias transformou-as em grandes produtoras de café, algodão e açúcar, justamente em um período no qual duas forças aparentemente contrárias se desenvolveram concomitantemente, o expansionismo do colonialismo britânico no Caribe meridional e o progressivo desmantelamento da escravidão negra (Browne, 2017) ${ }^{15}$.

Apesar da manutenção, pela administração britânica, dos códigos jurídicos holandeses, que se baseavam em tradições legais romanas, e da permanência de alguns plantadores na região, a influência do poder holandês nas três colônias diminuiu consideravelmente. $\mathrm{O}$ neerlandês e duas línguas crioulas, o Dutch Berbice o o Skepi, caíram rapidamente em desuso, se circunscrevendo a pequenas comunidades falantes (Robertson, 1989) ${ }^{16}$. A população de origem holandesa, já escassa no século XVIII, praticamente se extinguiu. ${ }^{17}$ Em contraponto, os valores culturais britânicos lançaram suas fundações e exerceram efeitos duradouros (Smith, 1956; 1962; Drummond, 1980; Jayawardena, 1968; Williams, 1991). Se em um punhado de décadas o poder e a hegemonia holandesa esvaneceram, não deixa de ser notável que representantes não-vivos dos colonizadores tenham logrado se enraizar na terra, como que imunes à transição da soberania holandesa para a britânica e, posteriormente, da transferência de poder da metrópole para um governo independente.

Em seu já citado artigo, Williams (2020[1990]) $)^{18}$ demonstrou habilmente como imagens sobre o passado colonial das populações guianenses desfavorecidas eram veiculadas (e armazenadas) por meio de rituais nos quais espíritos tomavam parte. Para explicar as especificidades de espíritos holandeses, os interlocutores de Williams traçavam paralelos entre o comportamento dos espíritos e as características que, estereotipicamente, associavam a colonizadores holandeses, remetendo não só às características dos colonizadores em vida como a episódios no decorrer da Revolta de Berbice. ${ }^{19}$ Dito de outro modo, ao pressuporem uma relação de homologia entre colonizadores e espíritos etnicamente identificados, guianenses identificam os espíritos como agentes da história, isto é, como membros de um estrato social que determina, em larga medida, os modos de ser e de ação dos espíritos (Cf. Trouillot, 2016: 52-53).

Williams entrecruza diversas ordens temporais e históricas, avançando interessantes reflexões sobre as relações entre rituais e história, ordens simbólicas e a identidade social de produtores de narrativas históricas. De meu ponto de vista, e $\mathbf{1 5}$ | Em pouco mais de dez anos, entre 1796 e 1807 , mais africanos(as) escravizados(as) foram deportados para Berbice, Essequibo e Demerara por negociantes britânicos do que por holandeses nos cem anos precedentes (Browne, 2017; Thompson, 1987).

16| Atualmente, não há ocorrência de falantes vivos de Skepi ou do Dutch Berbice creole.

17 | Como em outras colônias holandesas, colonos holandeses foram suplementados por contingentes expressivos de alemães e por agrupamentos de suíços, franceses, escandinavos e britânicos (Oostindie, 2012).

18|À exceção do fascinante artigo de Williams (2020 [1991]), poucos trabalhos se debruçaram sobre espíritos holandeses na Guiana. Referências mais gerais podem ser encontradas em Stephanides e Singh (2000), Younger (2010), Kloß (2016a) e Singer, Aaron e Araneta (1961).

19| As estórias sobre tesouros enterrados por holandeses no passado são particularmente ilustrativas. Os informantes de Williams reportaram que ao serem alertados da intenção de escravizados em saquear as plantações, "homens e mulheres holandeses reservaram tempo para enterrar seus pertences, antes de fugirem para manter suas vidas. Quem, a não ser aqueles cegos pela ganância (perguntam os informantes) teria tempo para enterrar seus pertences sob tais condições" (Williams, 2020: 205). Ouvi estórias - e lições morais-similares durante minha pesquisa de campo. Ver também Kars (2020:7-8) e seu relato sobre narrativas acerca de tesouros enterrados por holandeses nos arredores do Fort Nassau, em Berbice, onde diversos combates foram travados durante a Rebelião de Berbice. 
para os propósitos deste artigo, pode-se avançar ainda mais nas reflexões em torno de instâncias de produção de conhecimento histórico veiculadas, criadas e recriadas por e com espíritos. À medida que passei a ter contato próximo com pessoas afligidas por espíritos holandeses no templo de Kali onde concentrei minhas investigações, localizado na região de Berbice, passei a estimular toda e qualquer indivíduo com quem entabulava conversações a falar-me sobre o período holandês. Invariavelmente, as pessoas se referiam à infraestrutura hidráulica do país, à Revolta de Berbice e ao caráter cruel e ganancioso de colonizadores holandeses, aludindo a episódios que teriam ocorrido durante a revolta. Por sua vez, meus interlocutores e minhas interlocutoras principais indo-guianenses membros do culto à Kali - não só se referiam às mesmas coisas como detinham conhecimentos em primeira mão sobre os espíritos de holandeses. Como será visto a seguir, a vida em plantação legou heranças duradouras a indo-guianenses, e a membros do culto à Kali, em particular.

\title{
AS AMARCAS HERANÇAS DO AÇÚCAR
}

\author{
"Os indianos chegaram em uma terra onde ocorreram muitas \\ guerras e muitos assassinatos. Os holandeses eram pessoas \\ más, e fizeram muitas coisas cruéis [...] Eles [os espíritos] \\ estavam aqui antes de nós. Nós herdamos isso".
}

Ao evocar episódios que precederam o desembarque de trabalhadores sob contrato da Índia na então Guiana Britânica, entre 1838 e 1917, o sacerdote Bayo articula distintas ordens temporais sobrepostas umas às outras. Estimulado pelo meu interesse-e, evidentemente, por suas próprias reflexões-, Bayo discorria sobre espíritos holandeses para explicar-me o porquê da presença tão tenaz desses seres nas paragens guianenses. Como diversos outros interlocutores, no início de nossa conversa, Bayo aludiu ao massacre de holandeses por britânicos, aos suicídios coletivos e à ausência de ritos fúnebres adequados. No trecho acima reconstituído, um excerto de uma longa conversa ${ }^{20}$, Bayo estabeleceu nexos temporais (Cf. Hirsch e Stewart, 2005) entre a existência dos espíritos no presente e a transplantação de imigrantes da Índia para a Guiana Britânica no passado. Recém-chegados a uma colônia assolada por mortes violentas, os(as) imigrantes indianos passaram a viver em uma terra habitada por espíritos dos predecessores dos britânicos.

O desembarque de quase 240.000 trabalhadores e trabalhadoras da Índia na então Guiana Britânica decorre, basicamente, do empenho da administração colonial e de plantadores em garantir o suprimento de mão-de-obra barata para o trabalho agrícola nos anos subsequentes à abolição da escravidão negra no Caribe Britânico. ${ }^{21}$ As condições de vida de imigrantes da Índia eram precárias, e foram comparadas à

20| Em raras ocasiões tomei notas em frente de meus interlocutores. Durante toda a minha pesquisa de campo me servi do telefone celular para tomar notas, registrar diálogos, anotar frases e palavras-chave, rabiscar sistematizações, descrever os contextos e os cenários de interação, etc. Esse material bruto, armazenado em dispositivo eletrônico, serviu de complemento fundamental ao caderno de campo, sobre o qual me debruçava diariamente.

21| Durante a vigência do sistema de trabalho sob contrato, cerca de 340.000 pessoas provenientes da llha da Madeira, de territórios caribenhos vizinhos, da África, da Europa e da Ásia imigraram para a Guiana Britânica, entre 1835 e 1917 (Adamson, 1972). 
escravidão (Tinker, 1974). Após cruzarem o kala pani-as águas escuras-em uma jornada que durava aproximadamente 100 dias, homens e mulheres da Índia foram alojados nos antigos barracões ocupados por escravizados, cujas condições sanitárias eram deploráveis. Os contratos de trabalho - com duração de cinco anos ${ }^{22}$ - estabeleciam jornadas laborais extenuantes e mal remuneradas, limitavam o movimento pela colônia e previam diversas formas de punição aos imigrantes (Bahadur, 2013). De igual modo, os costumes, as línguas, ${ }^{23}$ o vestuário, a culinária e os hábitos alimentares, as marcas corporais (como tatuagens), dentre outras práticas de indianos, foram amplamente estigmatizadas, inclusive pela população de origem africana.

Em uma colônia cujos valores anglo-europeus eram hegemônicos (Drummond, 1980; Smith, 1967; Williams, 1991), a religião tornou-se um importante marcador de diferenciação. Com efeito, a tendência vitoriana de tratar a religião como metonímia da cultura e da civilização (Khan, 2012) concorreu para a racialização de indianos e indianas, que ocuparam um lugar marginal e periférico na sociedade colonial. Práticas religiosas de muçulmanos e de hindus ${ }^{24}$ foram rotuladas como pagãs, bárbaras e selvagens. Festivais religiosos públicos, casamentos costumeiros e demais rituais foram por muito tempo proibidos (Jayawardena, 1966), ao passo que missões cristãs foram estabelecidas já na década de 1850, ainda que não tenham logrado grande sucesso na conversão de almas (Look Lai, 1993).

A produção acadêmica especializada sobre a história do hinduísmo na Guiana dedica-se fundamentalmente a explorar dois grandes tópicos: os impactos do sistema de trabalho sob contrato sobre práticas religiosas e culturais de imigrantes e o processo de institucionalização de organizações religiosas que se pretendiam mais inclusivas e universais, como a Sanatan Dharma, a eterna verdade, em tradução literal (Jayawardena, 1966; Look Lai, 1993; McNeal, 2010; Younger, 2010). Essa vertente hindu emergiu na Guiana Britânica no final do século XIX, tornando-se em poucas décadas a vertente hindu hegemônica da colônia, a "base ideológica" da "consciência e da solidariedade grupal" indo-guianense (Jayawardena 1966: 232-233). Em paralelo, a emergência da Sanatan Dharma foi marcada pela estigmatização de práticas religiosas consideradas moralmente suspeitas, como o sacrifício de animais, a comunicação verbal direta entre devotos e divindades hindus e a mobilização destas em tratamentos terapêuticos. Reivindicando origens ortodoxas, bramânicas, sânscritas e norte-indianas, membros da Sanatan Dharma imputaram essas práticas a hindus de castas mais baixas e, em especial, a imigrantes originários do sul da Índia, os chamados Madrasis ${ }^{25}$. Deste modo, uma série de práticas religiosas hindus situou-se nas bordas das vertentes hindus oficiais (McNeal 2016; Kloß, 2016b; Younger, 2010).

Os estudos disponíveis sobre vertentes hindus heterodoxas como o culto à Kali dão pouca atenção às narrativas de seus próprios membros, além de restringirem suas observações a templos ou a grandes festivais religiosos (Bassier, 1977; McNeal, 2010; Singh, 1978; Stephanides e Singh, 2000; Younger, 2010). Deste modo, uma série
22 | Ao término desse período, o contrato de trabalho poderia ser renovado por mais cinco anos, o que facultava a interessados uma passagem de retorno à Índia. Cerca de 32\% do total de imigrantes retornou à Índia (Look Lai, 1993).

23 A maioria absoluta dos imigrantes - cerca de 90\% - provinha das Províncias Noroeste (Uttar Pradesh e Bihar, contemporaneamente), tendo embarcado para o Caribe a partir do porto de Calcutá (Kolkatta), enquanto o restante provinha do sul do subcontinente (Look Lai, 1993; Smith, 1959)

24 | Segundo Smith (1959), mais de $80 \%$ dos imigrantes da Índia eram hindus, enquanto cerca de $15 \%$ eram muçulmanos e apenas $1 \%$ cristãos.
$25 \mid$ Imigrantes do sul da Índia provinham de duas províncias de larga extensão territorial, Madras (Tamil Nadu, contemporaneamente) e Andhra Pradesh. Os embarques eram feitos no porto de Madras (Chennai). Embora rivalidades e diferenciações entre norte e sul-indianos já existissem no subcontinente, nas plantações caribenhas, como bem notou Khan (2004: 41; 2012: 36), a diversidade do subcontinente foi reduzida a um punhado de categorias contrastivas e identificadoras, como norte-indianos e Madrasis. 
de outras práticas foi ignorada, como a realização de ofertas rituais (pujas) em âmbito doméstico tanto para divindades familiares quanto para espíritos (ver, entretanto, Kloß, 2016a). Similarmente, o papel exercido por especialistas religiosos e divindades hindus no arbítrio das reivindicações territoriais de espíritos recebeu atenção diminuta.

Segundo Bayo, durante a época do sistema de trabalho sob contrato-também referido, por indo-guianenses, como o tempo da sujeição (bound time) -, diversas práticas religiosas da Índia foram duramente reprimidas por britânicos, em nome da fé cristã e da moralidade. Não obstante, as tradições se mantiveram, em larga medida graças à realização de pujas (ofertas rituais) em âmbito doméstico para deusas e deuses cultuados (worshiped) por antepassados, na Índia e na Guiana colonial. São as pujas familiares (também chamadas de ground pujas) que configuram aquilo que membros do culto à Kali chamam de herança. Embora herança remeta a um regime de descendência, não se trata de algo fixo no tempo. Isso é ilustrado pelo fato de novas heranças terem sido incorporadas aos repertórios de práticas hindus, precisamente porque durante o período de vigência do sistema de trabalho sob contrato, gerações de indianos(as) viveram no interior ou nas adjacências das moradas por excelência de espíritos holandeses, as plantações de açúcar.

Consequentemente, nas plantações de açúcar, indianas e indianos estavam sujeitos não apenas a jornadas de trabalho extenuantes, como eram constantemente ameaçados por ataques de espíritos de colonizadores que, insatisfeitos por não receberem compensações por suas perdas passadas, atentavam contra a vida de cortadores de cana-de-açúcar. Impossibilitados de conduzir livremente rituais para as divindades hindus em espaços públicos, os imigrantes passaram a realizar ofertas aos donos da terra, para se resguardar de suas ações malignas. Assim, a oferta continuada de itens como bebidas alcoólicas e animais sacrificados fez com que os espíritos fossem incorporados às pujas familiares.

Ao analisar a produção de relações entre pessoas, ancestrais mortos e os espíritos que habitam a terra, Dalmaso (2018) demonstrou que no Haiti certos lugares, como as habitasion e os lakou, "incorporam experiências ligadas simultaneamente ao passado e ao presente", estando diretamente relacionadas à noção de herança (ver também Bulamah 2015; Richman, 2014). Guardadas as devidas diferenças, gostaria de sugerir que no caso do culto à Kali na Guiana, a noção de herança aponta tanto para o caráter dinâmico de práticas rituais, como para noções de autoctonia que veiculam concepções locais sobre soberania, poder e direitos sobre a terra. Se, em diversos contextos, são os espíritos de povos ameríndios que são considerados primevos, originários e/ou autóctones (Bettelheim, 2005; Rabelo e Aragão, 2018; Santos, 1995; Strange, 2019), no caso da Guiana, são espíritos colonizadores que detêm essa condição, ao menos na percepção dos habitantes da região costeira do país.

Segundo Bayo e descendentes dos fundadores do templo de Blairmont, diante das constantes ameaças postas pelos espíritos, os próprios administradores das 
plantações de açúcar se convenceram da necessidade de resguardar os trabalhadores indianos de ataques espirituais. Cerentes e capatazes das plantações permitiam a realização de festivais hindus anualmente, liberando temporariamente as pessoas de suas jornadas de trabalho e até mesmo oferecendo contribuições financeiras para a aquisição dos itens necessários para os festivais hindus. Ao glorificarem divindades transplantadas da Índia para uma sociedade construída em torno das plantações de açúcar, os antepassados lograram ser protegidos por deuses e deusas e, por consequência, garantiam o próprio sucesso das colheitas de cana-de-açúcar. Curiosa e sintomática situação: o plantio e a colheita da cana-de-açúcar dependiam sobremaneira da ocorrência de festivais religiosos hindus ${ }^{26}$.

As estórias sobre a vida e a ocupação de plantações de cana-de-açúcar evocam, portanto, relações entre violência e perda, dominação, posse e exploração, inclusive no domínio da soberania territorial (ver Crosson, 2019; Johnson, 2011; 2019; Strange, 2019). Residir em áreas cercadas por usinas de cana-de-açúcar implica em habitar uma paisagem povoada por entes espirituais apegados a aquilo que está faltando: a posse dos bens e das riquezas produzidas pelo açúcar. A doçura do açúcar traz consigo a amargura da dominação, para parafrasear de modo um tanto selvagem Sidney Mintz (1985).

No caso de Blairmont, as relações com espíritos holandeses são fundacionais, pois o templo foi erigido, na década de 1940, sobre um Dutch spot, nas proximidades da Blairmont Sugar Factory, uma das poucas usinas de processamento de cana-deaçúcar ainda em operação no país, na qual diversos frequentadores do templo são empregados. À medida que pujas para as deusas e os deuses hindus passaram a ser realizadas com mais frequência, altares foram construídos e árvores - das quais frutos, plantas e flores para as pujas são extraído ${ }^{27}$ - foram plantadas no terreno, as divindades se estabeleceram no local, substituindo os espíritos.

Não obstante, as aparições de espíritos holandeses são frequentes em Blairmont. Não raro, eles assaltam devotos(as) durante as cerimônias religiosas, além de mimetizarem as divindades (Mello, 2020a). Para compreender como se dá a "comunicação corporificada" (Cf. Richman, 2014) com os espíritos, é necessário descrever de forma mais nuançada as formas de comunicação entre espíritos e humanos, os contextos de experiência nos quais esses encontros têm lugar (Blanes e Espírito Santo, 2013), os diversos modos de incorporação de espíritos no cotidiano da vida dos humanos (Espírito Santo e Tassi, 2013) e as estórias
26 | Essa concepção está relacionada à visão, largamente vigente entre indoguianenses, segundo a qual ao substituírem escravizados(as) no trabalho agrícola, os imigrantes indianos salvaram as plantações de açúcar-e, por extensão, o próprio país - da derrocada econômica.

27| Em outro lugar analise com vagar projetos de soberania territorial de humanos e espíritos holandeses, atentando para o papel de plantas e árvores nesse processo (Mello, 2021) 
contadas por espíritos sobre si mesmos e sobre humanos, e vice-versa (Cardoso, 2007). Sistemas locais de inferência que rastreiam, reconhecem e criam entidades espirituais (Blanes e Espírito Santo, 2013; Palmié, 2013; Wirtz, 2016) se assentam, no caso aqui em pauta, em narrativas acerca das circunstâncias de surgimento de espíritos. Esse conhecimento, historicamente informado, dos modos de ser e de agir dos espíritos remete, assim, não apenas a questões ontológicas (o que é) e epistemológicas (o que se sabe), mas também a referentes pragmáticos (o que fazer), afinal a presença de espíritos na terra demanda manipulações rituais, disputas e negociações.

\section{DIVINDADES HINDUS, ESPÍRITOS HOLANDESES E FORMAS DE COMPENSAÇÃO}

No templo de Kali de Blairmont, localizado na margem ocidental do Rio Berbice, devotos(as) congregam semanalmente para fazer puja (ofertar, rezar e reverenciar) um conjunto de divindades hindus. As divindades, que se manifestam nos corpos de certos especialistas religiosos, marlos ('médiuns'), transmitem mensagens oraculares e realizam tratamentos terapêuticos em pessoas acometidas por doenças, problemas domésticos, má-sorte, feitiçaria e ataques espirituais. Eventualmente, rituais são performados por sacerdotes em âmbito doméstico, como é o caso de locais habitados por espíritos.

O engajamento de divindades hindus em tratamentos terapêuticos é indissociável da atividade oracular. Toda e qualquer pessoa em busca de cuidado [look after] necessariamente deve se postar diante das manifestações divinas, reverenciá-las, e ouvir suas revelações. A divinação é um ponto de referência e de ação (Panagiotopoulos, 2018) fundamental no âmbito do culto à Kali. Mensagens oraculares não só apresentam novos elementos sobre acontecimentos do passado e do presente-e, portanto, influenciam o porvir (Lambek, 1981; Boddy, 1989) -, como produzem transformações nas próprias concepções que os humanos fazem de si próprios (Mello, 2020b; Ishii, 2016) ${ }^{28}$

Normalmente, então, consulentes interagem com divindades na posição de ouvintes, para descobrir, em primeiro lugar, as origens e as causas de seus problemas e suas aflições. Via de regra, as divindades prescrevem um período determinado de devoção aos consulentes. Ou seja, por alguns finais de semana, a pessoa em questão

$\mathbf{2 8}$ | Disso não decorre que vereditos divinos sejam prontamente, e acriticamente, aceitos. A dúvida, a hesitação e o ceticismo são elementos fundamentais no próprio processo de validação desses vereditos (Mello, 2020c). deve frequentar o templo, participar dos ritos, realizar ofertas e, eventualmente, iniciar o treinamento para manifestar divindades hindus, com o objetivo de incorporar o poder divino [shakti] em suas próprias essências corporais e morais (Mello, 2020c; Busby, 1997; Ishii, 2016; Marriott, 1976; Nabokov, 2001). Idealmente, à medida que as divindades se manifestam em humanos, os corpos destes se fortalecem e se tornam menos suscetíveis às influências de seres malévolos. Alternativamente, os procedimentos rituais podem se limitar à realização do chamado boundary work, ou seja, oferta ritual que visa compensar os espíritos holandeses pelas suas perdas passadas, de modo a aplacar seus desejos de vingança, prevenir ataques espirituais e reconhecer, ao menos 
parcialmente, seus direitos sobre a terra. De modo a deixar essas dinâmicas mais evidentes, detalho brevemente dois casos.

Aisha é uma guianense de meia-idade que imigrou para o Canadá há mais de trinta anos, onde vivia com o casal de filhos, ambos na faixa dos 20 anos de idade. Como milhares de conterrâneos, Aisha deixou a Guiana durante o governo de Forbes Burnham, em busca de melhores condições de vida. Já naquela época, disse-me, sua partida foi sem intenção de retorno. Entretanto, nem tudo ficou para trás. As dores corporais e os problemas de saúde que a acometiam desde sua adolescência persistiam, assim como relações conjugais instáveis. Desde muito nova, Aisha sabia que um espírito holandês, o grande responsável pelas desgraças que acometiam sua família natal, vivia na residência de seus pais na Guiana. O patriarca, todavia, era muçulmano convicto, e resistia às tentativas da filha de recorrer a sacerdotes do culto à Kali. Ademais, havia temores quanto à reputação da família, pois os membros da mesquita do vilarejo provavelmente não aprovariam o envolvimento de um de seus membros com o povo de Kali.

Aisha concebeu os dois filhos muito jovem e foi obrigada a abandonar o marido (um indivíduo mulherengo, agressivo e afeito à jogatina) antes mesmo do nascimento da caçula. No Canadá, casou-se outra vez, mas novamente o companheiro proporcionouIhe mais tristezas do que alegrias. A filha estava doente há anos, e nem várias consultas médicas, nem baterias de exames, identificaram qualquer enfermidade. O filho, por sua vez, estava desempregado, apesar de qualificado profissionalmente. Aisha visitava os pais na Guiana sempre que possível, dentre outros motivos porque se preocupava com a débil saúde de seu pai, adoecido há anos. Inesperadamente, e contrariando todas as expectativas, foi sua mãe, que gozava de excelente saúde, quem morreu, subitamente. Trinta anos de uma vida atribulada a motivaram a procurar ajuda em outros lugares e, por meio de uma amiga de infância, Aisha decidiu visitar Blairmont, semanas após perder a mãe. Além do luto pela perda familiar, seus sonhos passaram a ser assolados pelo espírito, o que resultava em dores corporais e torpor mental ${ }^{29}$. Sim, confessou-me, tinha reservas para com aquela vertente hindu, em virtude de suas origens muçulmanas. Entretanto, seu desespero era tamanho que decidiu ignorar seus preconceitos.

Em uma de suas visitas a Blairmont, Aisha se pôs a chorar copiosamente ao ser interpelada pela deusa Mariamma, logo após ela afirmar, peremptoriamente, que a situação de Aisha era extremamente grave, exigindo um boundary work. Dias depois, Aisha recebeu sacerdotes de Blairmont na residência de seu pai, com anuência deste. Embora não tenha acompanhado esse ritual em âmbito doméstico, soube, pelos envolvidos, que a vida de Aisha não prosperava precisamente porque o senhor daquele lugar (ou seja, o espírito) não recebia nenhuma forma de compensação há anos. Ao se incorporar em um especialista religioso, o próprio espírito evidenciou isso, queixandose de ter sido esquecido. Aisha regressou ao Canadá dias depois e perdi contato com

29| Em suas conversas comigo, Aisha foi reticente quanto à ocorrência de ataques sexuais do espírito no plano onírico. Documentei outros casos de pessoas atacadas sexualmente por espíritos. Por motivos de espaço, não abordarei essa questão aqui. 
ela. Meses depois, tive notícias indiretas suas, quando o tesoureiro do templo, em tom jocoso, informou a todos que a vida da fulah ga ${ }^{30}$ havia progredido tanto, já que seus problemas foram deixados para trás, que ela resolvera fazer uma doação financeira generosa para o templo.

José, por sua vez, tinha uma vida extremamente tranquila até o momento em que passou a ser atacado por um espírito holandês, o que alterou completamente sua disposição de espírito - com o perdão do trocadilho. José, um homem estimado por sua afabilidade, tornou-se agressivo e passou a consumir incessantemente

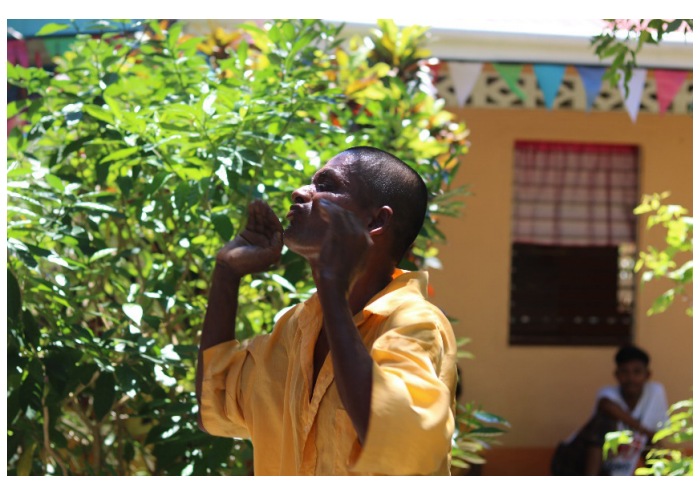

Um espírito holandês irrompe em um rito de Kali. Novembro de 2018. os estoques de cerveja e rum que abasteciam seu bar. Frequentador assíduo de Blairmont, José se ausentou dos rituais, até porque estava sempre impuro, o que o impedia de participar dos rituais ${ }^{31}$. Sua situação se deteriorou a tal ponto, entretanto, que o sacerdote autorizou sua presença no local quando sua família o arrastou à força ao templo. Naquele domingo de setembro de 2011, José, visivelmente embriagado, foi possuído pelo espírito, que passou a mimetizar os movimentos das divindades hindus, como se fosse uma delas.

O deus que conduzia um ritual de cura em José na ocasião, se enfureceu a tal ponto com a conduta do espíritoque passou a golpear o corpo de José violentamente com um ramo de folhas da árvore sagrada neem, até este recuperar seus sentidos. Ainda um tanto cambaleante, José foi levado, incontinenti, à deusa Mariamma, que Ihe prescreveu um boundary work. Dias depois, seis membros de Blairmont se reuniriam na casa de José, que havia disposto, conforme as recomendações de sacerdotes, uma pequena mesa no centro de sua sala, na qual diversos itens, como alimentos, bebidas alcóolicas e cigarros, estavam dispostos. Ricky, um jovem marlo (médium) de Blairmont, ficara responsável por invocar o espírito em si mesmo (call up the Dutch upon himself) ${ }^{32}$, para que todos pudessem ouvi-lo.

Por motivos de espaço, não reconstituirei em minúcias aqui todo esse caso, nem a interação entre José, sua família, membros de Blairmont e o espírito nessa ocasião (Mello, 2020a). Limito-me a chamar a atenção para três aspectos. Em primeiro lugar, as razões para os ataques foram logo evidenciadas pelo próprio espírito, que aludiu ao péssimo hábito de José, quando bêbado, de fazer libações para toda sorte de ente espiritual, menos para o verdadeiro senhor do local - não por coincidência, o espírito que ali se encontrava. Em segundo lugar, à essa conduta somou-se um longo esquecimento: nem José, nem sua família, compensavam [rewarded] o senhor da terra há longos anos. Por fim, o espírito tinha um forte sotaque, pois não tinha muita
30| Termo ofensivo utilizado por hindus em referência a indianos(as) muçulmanos. A identificação de muçulmanos com uma etnia africana sugere, para hindus, que indoguianenses muçulmanos não professam a religião tradicional da Índia, o hinduísmo. Cal é o equivalente fonético, na língua crioula da Guiana, o creolese, da palavra girl.

31 | Consulentes e membros do culto à Kali devem abster-se do consumo de bebidas alcóolicas, de fibra animal e de contrair relações sexuais por três dias antes de frequentarem os cerimoniais religiosos.

32 | A manifestação de espíritos holandeses é restrita, até onde sei, a homens, e envolve uma série de procedimentos rituais, não raro secretos, para se concretizar. Para membros do culto à Kali, quem manifesta um espírito holandês necessariamente deve manifestar divindades hindus, pois a incorporação do poder (shakti) das divindades nos corpos das pessoas não só fortalece suas essências corporais, como previne ataques de seres maléficos. 
fluência em inglês. O tom gutural de suas palavras evocava ordens profundas, que nem sempre ecoavam entre seus interlocutores, que progressivamente desistiram de tentar entender tudo que era dito, limitando-se a seguir o rumo da conversação. Após a realização desse ritual, no qual o espírito se fez presente por mais de uma hora, a hostilidade do dono da terra para com José cessou, e este parou de beber, recuperando seu ânimo original.

Os casos de Aisha e José evidenciam que a expressão dos pontos de vista dos espíritos depende de uma série de mediações, ainda que possa se dar diretamente, por meio da possessão espiritual. No plano onírico, suas aparições ganham contornos espectrais e difusos; nos templos de Kali, a força de suas mensagens depende da atividade oracular das divindades; e nos rituais domésticos, especialistas religiosos têm um papel determinante no reconhecimento da autoctonia territorial dos espíritos. Incapazes de se comunicarem plenamente na própria língua, espíritos holandeses se engajam diretamente na criação de meios alternativos de veiculação e armazenamento de suas estórias.

\section{CONSIDERAÇÕES FINAIS}

As reverberações de um passado distante, e tão íntimo, parecem percorrer caminhos inextricáveis quando assoladas por atos violentos embebidos na terra. Como deixei evidente, os próprios guianenses associam os modos de ser e as origens de espíritos holandeses ao passado colonial, a episódios da história nacional guianense e às plantações de açúcar. Informados pelas estórias dos espíritos, pelo histórico de coabitação com estes, por mensagens oraculares de divindades hindus, por experiências no plano onírico e por narrativas sobre a ocupação da terra, homens e mulheres do culto à Kali produzem reflexões e adquirem conhecimento em primeira mão sobre episódios imersos no passado colonial da Cuiana.

Para meus interlocutores e minhas interlocutoras, os ataques de espíritos replicam o comportamento violento, ganancioso e traiçoeiro de colonizadores que, em vida, foram vitimados por um poder colonial exógeno - dos britânicos, no caso. $A$ reincidência de sofrimentos, perdas e dores vivenciados por colonizadores holandeses parecem despertar, como bem notou Williams (2020), um desejo insaciável dos espíritos de asseverar a realidade de suas existências. As reivindicações de soberania territorial dos espíritos exigem, dos humanos, o reconhecimento dos traços e rastros dos efeitos produzidos por espíritos no mundo, particularmente aqueles inscritos na paisagem (Brown, 2008; Mueggler, 2001; Shaw, 2002).

O sistema hidráulico guianense parece constituir testemunho bastante eloquente da herança holandesa no país, na medida em que, como nota Trouillot (2016), a materialidade do processo histórico (historicidade 1, nos seus termos) contribui para a definição do cenário para futuras narrativas históricas (historicidade 2). Assim, "o que aconteceu deixa indícios, alguns dos quais bastante concretos-edifícios, cadáveres, 
censos, monumentos, diários, fronteiras políticas-que limitam o alcance e o significado de qualquer narrativa histórica". No entanto, tais formas materiais não conferem, por si só, força a narrativas históricas, cuja produção envolve a "desigual contribuição de grupos e pessoas concorrentes, que têm acesso desigual aos meios dessa produção" (Trouillot, 2016: 17-18). Na concepção de Trouillot, a materialidade do processo histórico não implica que os fatos já estejam dados e prontos para serem descobertos; antes, trata-se de reconhecer que "a história começa com corpos e artefatos: cérebros vivos, fósseis, textos, edifícios" (Trouillot, 2016: 61). A história oral não escapa a tal regra, embora, no que lhe diga respeito, "o momento da criação do fato é continuamente prolongado nos próprios corpos das pessoas que participam dessa transmissão. $A$ fonte é viva" (Trouillot, 2016: p. 61, nota 3) [grifos no original]).

Essa última formulação pode ser adaptada para o caso aqui em pauta, na medida em que espíritos são fontes vivas não tanto porque apresentam testemunhos já prontos sobre eventos passados, mas porque inscrevem, por meio de diversas ordens de mediação, os legados e as heranças do passado colonial em edificações, ruínas $^{33}$, na paisagem e nos próprios corpos de guianenses. Deste modo, a própria imediaticidade de experiências sensoriais originais (Cf. Palmié e Stewart, 2019) dos espíritos é visceralmente experenciada, não raro coercitivamente, por guianenses no 33 Para uma análise das relações entre ruínas e sensos históricos nativos, ver: Bulamah (2018); Collins (2015) e Gordillo (2014). presente. Espíritos se servem de corpos humanos para expressar seus pontos de vista e desejos, bem como para contar suas estórias. Estabelecem canais de comunicação em diversos domínios da experiência, mesmo aqueles difusos, como sonhos. Inebriam suas vítimas para torná-las confusas. Ao reivindicarem a condição de senhores da terra, tornam os corpos de humanos em lócus de replicação, reprodução e transmissão de suas estórias, transformando-os em repositórios (arquivos, se quisermos) dos legados do período colonial.

Disso não decorre que espíritos ajam impunemente, ou que suas estórias sejam meramente reproduzidas por humanos. Em rituais hindus, especialistas religiosos e divindades confrontam os espíritos, buscam mitigar os efeitos de suas ações, restringir seu raio de alcance. Nas narrativas sobre a transplantação do culto à Kali para a Guiana, a existência primeva dos espíritos ganha destaque, bem como outras dimensões centrais das vidas de devotos de Kali, como o histórico de ocupação da terra e a criação de espaços religiosos. Espíritos não são meras evocações de lembranças dolorosas de eventos passados. Na Guiana, suas influências, extensões e multiplicações no mundo (Cf. Blanes e Espírito Santo, 2013) assumem contornos materiais e imateriais. Se as narrativas que associam a própria gênese do país à intervenção colonial holandesa na paisagem encontram na infraestrutura colonial uma espécie de testemunho, são os representantes não-vivos de colonizadores que tornam o passado imperfeito, gramatica e ontologicamente (Lambek, 1996; 2016). A julgar pelas narrativas amplamente difundidas na região costeira da Guiana, massacres e suicídios não anularam a presença holandesa no país. Ao tornaram-se íntimos de trabalhadores de cana-de-açúcar e de 
seus descendentes, os sobreviventes desincorporados (e sem túmulos para repousar) de colonizadores holandeses continuam a fazer irromper as heranças e os fardos do passado colonial.

Marcelo Moura Mello é Professor Adjunto do Departamento de Antropologia e Etnologia e pesquisador do Centro de Estudos Afro-Orientais, Universidade Federal da Bahia.

CONTRIBUIÇÃO DE AUTORIA: Não se aplica

FINANCIAMENTO: Esta pesquisa recebeu financiamento da Universidade Federal da Bahia, por meio do Programa de Apoio a Jovens Doutores (Edital 004/2016) e por meio do Edital ProCEAO (Edital 01/2017).

\section{REFERÊNCIAS BIBLIOGRÁFICAS}

ADAMSON, Alan. 1972. Sugar Without Slaves: the political economy of British Guiana, 18381904. New Haven: Yale University Press.

BAHADUR, Gaiutra. 2013. Coolie Woman. The odyssey of indenture. Chicago: The University of Chicago Press.

BASSIER, Dennis. 1977. Kali Mai Worship in Guyana. An overview. Georgetown: University of Guyana.

BETTELHEIM, Judith. 2005.

"Caribbean espiritismo (Spiritist) altars: the Indian and the Congo". The Art Bulletin v. 87, n. 2: 312-330.

BLANES, Ruy; ESPÍRITO SANTO, Diana. 2013. "Introduction. On the agency of intangibles". In: BLANES, Ruy e ESPÍRITO SANTO, Diana (eds.). The social Life OfSpirits. Chicago: The University of Chicago Press: pp.1-32.
BOODY, Janice. 1989. Wombs and Spirits. Women, men, and the Zar cult in Northern Sudan. Madison: The University of Wisconsin Press.

BROWN, Vincent. 2008. The Reaper's Garden. Death and power in the world of Atlantic slavery. Cambridge, Harvard University Press.

BROWN, Vincent. 2010. "History attends to the dead". Small Axe, n. 31: 219-227. https:// doi.org/10.1215/07990537-2009-054

BROWNE, Randy. 2017. Surviving Slavery in the British Caribbean. Philadelphia: University of Pennsylvania Press.

BULAMAH, Rodrigo. 2015. "Um lugar para os espíritos. Os sentidos do movimento desde um povoado haitiano". Cadernos Pagu, n. 45: 79-110. https://doi.org/10.1590/18094449201500450079

BULAMAH, Rodrigo. 2018. Ruínas circulares: vida e história no norte do Haiti. Campinas. 
Tese de Doutorado. Campinas, Universidade de Campinas.

BUSBY, Cecilia. 1997. "Permeable and partible persons: a comparative analysis of gender and body in South India and Melanesia". JRAI v. 3, n. 2: 261-278. https://doi.org/10.2307/3035019

CARDOSO, Vânia. 2007. "Narrar o mundo: estórias do 'povo de rua' e a narração do imprevisível". Mana-Estudos de Antropologia Social v.13, n.2: 317-345. https://doi. org/10.1590/S0104-93132007000200002

COLLINS, John. 2015. Revolt of The Saints. Memory and redemption in the twilight of Brazilian racial democracy. Durham: Duke University Press.

CROSSON, J. Brent. 2019. "'What possessed you? Spirits, property, and political sovereignty at the limits of 'possession'". Ethnos-Journal of Anthropology, v. 84, n. 4: 546-556. https:// doi.org/10.1080/00141844.2017.1401704

DALMASO, Flávia. 2018. "Heranças de família: terras, pessoas e espíritos no sul do Haiti". Mana - Estudos de Antropologia Social, v. 24, n. 3: 96-123. https://doi. org/10.1590/1678-49442018v24n3po96

DESPRES, Leo. 1967. Cultural Pluralism and Nationalist Politics in British Guiana. Chicago: Rand McNally.

DRUMMOND, Lee. 1980. "The cultural continuum: a theory of intersystems". Man, v. 15, n. 2: 352-374. https://doi.org/10.2307/2801676

EDWARDS, Duane. 2016. "Suicide in Guyana: a Parsonian corrective to Durkheim's theory of suicide". Canadian Journal of American and Caribbean Studies, v. 41, n. 2: 197-214. https:// doi.org/10.1080/08263663.2016.1189650
ESPÍRITO SANTO, Diana; TASSI, Nicolas (Eds.). 2013. Making Spirits. Materiality and transcendence in contemporary religions. London: I. B. Tauris.

FARAGE, Nádia. 1992. As muralhas do Sertão: os povos indígenas no Rio Branco e a colonização. Rio de Janeiro: Anpocs/Paz e Terra.

FORDE, Maarit. 2018. "Introduction”. In: FORDE, Maarit e HUME, Yanique (eds.). Passages and Afterworlds. Anthropological perspectives on death in the Caribbean.

Durham: Duke University Press, pp. 1-27.

GORDILLO, Gastón.2014. Rubble. The Afterlife of Destruction. Durham: Duke University Press.

HINTZEN, Percy. 1989. The Costs of Regime Survival. Racial mobilization, elite domination and control of the state in Cuyana and Trinidad. Cambridge: Cambridge University Press.

HIRSCH, Eric; STEWART, Charles. 2005. "Introduction: ethnographies of historicity". History and Anthropology v. 16, n. 3: 261-274. https://doi.org/10.1080/02757200500219289

JAYAWARDENA, Chandra. 1966. "Religious belief and social change. Aspects of the development of Hinduism in British Guiana". Comparative Studies in Society and History 8(1): 211-240.

KARS, Marjoleine. 2020. Blood on the river. A chronicle of mutiny and freedom on the Wild Coast. New York: New Press.

KHAN, Aisha. 2004. Callaloo Nation. Metaphors of Race and Religious Identity among South Asians in Trinidad. Durham: Duke University Press.

KHAN, Aisha. 2012. "Islam, vodou, and the making of the Afro-Atlantic". New West Indian Guide v. 86, n.1-2: 29-54.

KLOß, Sinah. 2016a. Fabric of Indianness. The exchange and consumption of clothing in 
transnational Cuyanese Hindu communities. New York: Palgrave MacMillan.

KLOß, Sinah. 2016b. Manifesting Kali's Power: Guyanese Hinduism and the Revitalisation of the "Madras Tradition'." Journal of Eastern Caribbean Studies 41(1): 8

KLOOSTER, Wim; OOSTINDIE, Cert. 2018. Realm Between Empires. The second Dutch Atlantic, 1680-1815. Ithaca: Cornell University Press.

KWON, Heonik. 2008. Chosts of War in Vietnam. Cambridge: Cambridge University Press.

LAMBEK, Michael. 1981. Human Spirits: A Cultural Account of Trance in Mayotte. Cambridge, Cambridge University Press.

LAMBEK, Michael. 2016. "On being present in history: historicity and Brigadian spirits in Madagascar". Hau-Journal of Ethnographic Theory, v. 6, n. 1: 317-341. https://doi.org/10.14318/hau6.1.018

LOOK LAI, Walter. 1993. Indentured Labour, Caribbean Sugar. Chinese and Indian migrants to the British West Indies, 1838-1918. Baltimore: John Hopkins University Press.

MARRIOTT, McKim. 1976. "Hindu transactions: diversity without dualism." In: KAPFERER, Bruce (ed.). Transaction and meaning, Philadelphia: Institute for the Study of Human Issues, pp.109-142.

MATOS, Beatriz. 2017. "O ataque das pessoas e a desconstituição da pessoa entre os Matses". In: APARICIO, Miguel; CAMPO ARAÚZ (org.). Etnografías del suicidio en América del Sur. Quito: Editorial Universitaria Abya-Yala. pp. 149-170.

McNEAL, Keith. 2010. Trance and modernity in the Southern Caribbean. Gainesville: The University of Florida Press.
MELLO, Marcelo Moura. 2021 [prelo]. "Dutch Spirits, East Indians, and Hindu deities in Guyana: contests over land." American Anthropologist.

MELLO, Marcelo Moura. 2020a. Mimesis, dúvida e poder: divindades hindus e espíritos de colonizadores na Guiana. Horizontes Antropológicos, v. 26, n. 1: 57-86. https://doi. org/10.159o/s0104-71832020000100004

MELLO, Marcelo Moura. 2020b. "Articulação oracular e pesquisa de campo". Aceno-Revista de Antropologia do Centro-Oeste v. 7, n. 13: 35-52.

MELLO, Marcelo Moura. 2020c. "Materiality, affection, and personhood: on sacrifice in the worship of the goddess Kali in Guyana". Vibrant - Virtual Brazilian Anthropology v. 17, n. 1: 1-20. https://doi.org/10.1590/1809-43412020v17d506

MENTORE, George. 2018. "Of vital spirit and precarious bodies in Amerindian socialities". In: FORDE, Maarit \& HUME, Yanique (eds.). Passages and Afterworlds. Anthropological perspectives on death in the Caribbean. Durham: Duke University Press, pp. 54-79.

MINTZ, Sidney. 1985. Sweetness and Power. The place of sugar in modern history. New York: Penguin Press.

MUECGLER, Eric. 2001. The Age OfWild Chosts. Memory, violence, and place in Southwest China. Berkeley: The University of California Press.

NABOKOV, Isabelle. 2000. Religion Against The Self. An ethnography of Tamil rituals. Oxford: Oxford University Press.

OOSTINDIE, Gert. 2012. "'British Capital, Industry and Perseverance' versus Dutch 'Old School'? The Dutch Atlantic and the Takeover of Berbice, Demerara and Essequibo, 1750-1815". Low Countries Historical Review, v. 127, n. 4: 28-55.

PALMIÉ, Stephan. 2013. "Historicist knowledge and its conditions of impossibility". In: 
BLANES, Ruy \& ESPÍRITO SANTO, Diana (eds.). The Social Life of Spirits. Chicago, The University of Chicago Press, pp. 218-240.

PALMIÉ, Stephan. 2002. Wizards \& Scientists. Explorations in Afro-Cuban modernity and tradition. Durham: Duke University Press.

PALMIÉ, Stephan \& STEWART, Charles. 2019. "Introduction: the varieties of historical experience". In: PALMIÉ, Stephan \& STEWART, Charles (eds.). The varieties of historical experience. London: Routledge, pp. 1-29.

PALMIÉ, Stephan \& STEWART, Charles 2016. "Introduction: for an anthropology of history”. Hau-Journal of Ethnographic Theory, v. 6, n. 1: 206-227. https://doi.org/10.14318/hau6.1.014

PANAGIOTOPOULOS, Anastasios. 2018. "Food-for-words: sacrificial counterpoint and oracular articulacy in Cuba". HauJournal of Ethnographic Theory v. 8, n. 3: 474-487. https://doi.org/10.1086/700980

PECHINCHA, Monica. 2018. "Aportes da etnografia sul-americanista ao entendimento dos suicídios indígenas: uma tentativa de síntese a partir de noções divergentes de 'psique'/'alma'. Anuário Antropológico, v. 1: 223-256. https://doi.org/10.4000/aa.2965

PIRES, Rogério; STRANCE, Stuart; MELLO, Marcelo Moura. 2018. "The Bakru speaks: Money-making demons and racial stereotypes in Guyana and Suriname". New West Indian Guide v. 92, n. 1-2: 1-34. https:// doi.org/10.1163/22134360-09201001

RABELO, Miriam; ARACÃO, Renato. 2018. "Caboclos e orixás no candomblé: modos de conexão e possibilidades de simbiose". Religião \& Sociedade v. 38, n. 1: 84-109. https:// doi.org/10.159o/0100-85872018v38n1capo4
RIVIÈRE, Peter. 1981. Individual and society in Guyana. A comparative study of Amerindian social organization. Cambridge: Cambridge University Press.

RODNEY, Walter. 1981. A history of the Guyanese working-class people, 1881-1905. Baltimore: John Hopkins University Press.

RICHMAN, Karen. 2014. "Possession and attachment: notes on moral ritual communication among Haitian descendent groups". In: JOHNSON, Paul (ed.). Spirited things. The work of 'possession' in Afro-Atlantic religions. Chicago: The University of Chicago Press, pp. 225-255.

ROBERTSON, lan. 1989. "Berbice and Skepi Dutch: a lexical comparison". In: Tijdschrift voor Nederlandse Taal-en Letterkunde 105: 3-21.

SANTOS, Jocélio. 1995. O dono da terra. O caboclo nos candomblés da Bahia. Salvador: Sarah Letras.

SAHLINS, Marshall. 1985. Islands of history. Chicago: The University of Chicago Press.

SHAW, Rosalind. 2002. Memories of the Slave Trade: Ritual and the Historical Imagination in Sierra Leone. Chicago: The University of Chicago Press.

SIMMEL, Georg. 1958 [1912]. "The ruin". The Hudson Review, v. 11, n. 3: 379-385.

SINGER, Philip; AARONS, Louis; ARANETA, Enrique. 1967. "Integration of indigenous healing practices of the Kali cult with Western psychiatric modalities in British Guiana". Revista interamericana de psicología, v. 1, n. 2:103-113.

SINGH, Karna. 1978. Kali Mai Puja. A Study of a Guyanese East Indian folk cult in its sociocultural context. Georgetown: University of Guyana.

SMITH, Raymond. 1956. The Negro family in British Guiana. Oxford: Clarendon Press. 
SMITH, Raymond. 1959. "Some social characteristics of Indian immigrants to British Guiana". Population Studies 13: 34-39.

SMITH, Raymond. 1962. British Guiana. Oxford: Oxford University Press.

SMITH, Raymond. 1995. "Living in the gun mouth': race, class and political violence in Guyana". New West Indian Guide, v. 69, n. 3-4: 223-252.

STEPHANIDES, Stephanos; SINGER, Karna. 2000. Translating Kali's feast. The goddess in in Indo-Caribbean ritual and fiction. Amsterdam: Rodopi.

STEWART, Charles. 2016. "Historicity and anthropology". Annual Review of Anthropology, v. 45: 79-94. https://doi. org/10.1146/annurev-anthro-102215-100249

STRANGE, Stuart. 2019. "Indigenous spirits, pluralist sovereignty and the aporia of Surinamese Hindu belonging". Ethnos Journal, v. 84, n. 4: 642-659.

https://doi.org/10.1080/00 141844.2017.1381632

TAYLOR, Moe. 2020. "Walter Rodney, Forbes Burnham, and the spectre of pseudo-socialism." Canadian Journal of Latin American and Caribbean Studies v. 45, n. 2: 193-211. https://doi.org/1 $0.1080 / 08263663.2020 .1733850$

THOMPSON, Alvin. 1987. Colonialism and underdevelopment Guyana, 1580-1603. Bridgetown: Carib Research \& Publications Inc.

TINKER, Hugh. 1974. A new system of slavery. The export of Indians overseas. London: Hansib.
TROUILLOT, Michel-Rolph. 2016

[1995]. Silenciando o passado. Poder e a produção da história. Curitiba: Huya.

TROTZ, Alissa. 2003. "Between despair and hope: women and violence in contemporary Guyana". Small Axe, v. 15, n. 1: 1-20. https://doi.org/10.1215/-8-1-1

VIDAL, Silvia; WHITEHEAD, Neil L. 2004. "Dark shamans and the shamanic state. Sorcery and witchcraft as political process in Guyana and Venezuelan Amazon". In: WHITEHEAD, Neil L.; WRIGHT, Robin (eds.). In Darkness And Secrecy. The anthropology of assault sorcery and whitchcraft in Amazonia. Durham: Duke University Press, pp. 51-82.

WHITAKER, James. 2016. "Amerindians in the $18^{\text {th }}$ Century Plantation system of the Guianas". Tipití-Journal of the Society for the Anthropology of Lowland South America, v. 14, n. 1: 30-43.

WHITEHEAD, Neil. 2002. Dark shamans. Kanaimà and the poetics of violent death. Durham: Duke University Press.

WILLIAMS, Brackette. 2020 [1990]. "Fantasmas holandeses e o mistério da história: ritual e interpretações de colonizados e colonizadores sobre a Rebelião de Escravos de Berbice de 1763". Ilha, Revista de Antropologia, v. 22, n. 1: 187-233. http://dx.doi. org/10.5007/2175-8034.2020V22n1p187

WILLIAMS, Brackette. 1991. Stains on my name, war in my veins. Guyana and the politics of cultural struggle. Durham: Duke University Press.

WHITAKER, James. 2016. "Amerindians in the $18^{\text {th }}$ Century plantation systems of Guiana". Tipití-Journal of the society for the anthropology of lowland South America, v. 14, $n^{0}$ 1: 4-30. 
WIRTZ, Kristina. 2016. "The living, the dead, and the immanent. Dialogues across chronotopes". Hau-Journal of Ethnographical Theory, v. 6, n. 1: 343-369. https://doi.org/10.14318/hau6.1.019
YOUNGER, Paul. 2010. "Guyana: invented traditions". In: YOUNGER, Paul. New homelands. Hindu communities in Mauritius, Guyana, Trinidad, South Africa, Fiji and East Africa. Oxford: Oxford University Press, pp. 55-94.

Recebido em 27 de setembro de 2019. Aceito em 18 de março de 2021. 